\title{
High-Cited Papers on Covid-19 Research: A Scientometric Analysis
}

\author{
SM Dhawan', M Surulinathi2 ${ }^{2,},{ }^{1}$, BM Gupta ${ }^{3}$ \\ 'Formerly with CSIR-NPL, New Delhi, Delhi, INDIA. \\ ${ }^{2}$ Bharathidasan University, Department of LIS, Tiruchirappalli, Tamil Nadu, INDIA. \\ ${ }^{3}$ Formerly with CSIR-NISTADS, New Delhi, Delhi, INDIA.
}

\begin{abstract}
Aim: The paper presents a bibliometric analysisis of high-cited papers (HCPs) on Covid-19 published during 2019-2021. The study provides evidence on current research trends in the subject, identifies influential countries, organizations, research papers and journals on Covid-19 research. The study evaluates publication and citation performance of highly-cited papers and maps network interactions amongst the key global players using VOSviewer software. Materials and Methods: The data for the study was sourced from Web of Science for the period 2019-2021. Results: The USA, China and the UK dominate global Covid-19 research in terms of research productivity. In terms of citation performance China leads the tally with the USA at the second position. The USA, China and the UK account for a $88 \%$ share of total HCPs in the subject. The study identified top eleven centers of excellence based on the criteria of most productivity as well as most-cited organizations. New England Journal of Medicine,
\end{abstract}

Lancet, JAMA - Journal of the American Medical Association, Science and Nature are the most favoured journals for publishing HCPs. The relationship networks of most productive countries, organizations, and keywords are also given in the paper.

Key words: Covid-19, High-Cited Papers, Social network analysis, Scientometrics, Bibliometrics.

Correspondence

M Surulinathi,

Bharathidasan University, Department of LIS, Tiruchirappalli, Tamil Nadu, INDIA.

Email id: surulinathi@gmail.com

DOI: 10.5530/jyp.2021.13s.64

\section{INTRODUCTION}

Of late, Covid science has come to witness a sharp and sudden increase in research articles in the subject initially during the first pandemic wave and later during the second pandemic wave covering the period 2019-21. A recent study reported that well over 100,000 papers related to coronavirus pandemic were published in 2020 alone $^{1}$ Some of the underlying factors that seem to have fuelled this kind of trend include 'no proven cure' 'relatively high mortality rate,' 'urgency to discover Covid medicines, and drugs and vaccines discovery' STM publishers in health and medicines sector have also started witnessing huge rise in the submissions of manuscripts for publication in their journals. They have appropriately responded to the heightened demand trend, like fast speed up their manuscript review and online publication process. In select cases, submission to publication process time has since shirked to just three days. ${ }^{1}$ Given the pace at which scholarly publishing trends are changing and in a significant way, it would be relevant if a bibliometric study is undertaken to understand the current research trends as well as ascertain the status of research in Covid-19 at the global, national, institutional, and journal level. High-cited papers tend to highlight breakthrough trends within a given field, regarded as most influential papers, stand a greater chance of visibility and have a greater potential to attract attention of researchers in the subject. ${ }^{2}$ Given this context, it will therefore be even more appropriate if such a bibliometric study is conducted based on data relating only to high-cited publications in Covid-19.

\section{Literature Review}

A number of bibliometric studies on high-cited papers on Coronovirus and Covid-19 were carried out during the last 2 years. For instance, Khalid Farooq, Ashiq, Siddique, Rehman, Adil, and Ajmal Khan ${ }^{3}$ identified and examined in their paper the characteristics of 296 high-cited and hot papers on Coronavirus and Covid-19 from Web of Science database till 18 July 2020. The distributions of high-cited papers and hot papers per year were analyzed by country of publication, organization and journal, as well as analysed by authorship pattern and most frequently used keywords. Ram and Nisha ${ }^{4}$ in their paper analyzed 806 high-cited articles published during 1979-2019, using Scopus database till 30 March 2020. The authors analyzed the citation life cycle of the high-cited articles, performance of authors, institutions, country, and journals.

Among studies focusing on Covid-19, Kambhampati, Vasudeva, Vaishya and Patralekh ${ }^{5}$ examined the top 50 high-cited articles on Covid-19, using e-utilities in PubMed till 7.2.2021. The top 50 most-cited articles identify the most impactful studies on Covid-19, providing educators a useful resource as well as identifying such trends as are useful in guiding on-going research and publishing efforts. These 50 articles received 123,960 citations, the highest being 10,754 citations to a single article. C. Huang was the most-cited first author. Lancet was the most-cited journal, having published 9 articles. Majority of the studies belonged to level-3 of the evidence ladder and were classed as retrospective studies. Thirty per cent of the total articles had an errata published and an average of 7 comments per article. Afshar and Tabrizi ${ }^{6}$ examined 100 high--cited papers on Covid-19, using Scopus database on 6 August 2020. The authors identified and analysed the publications for the geographic region, language and number of citations as well as the publishing journal. Twenty-nine countries contributed to the 100 high-cited articles, with China and USA leading with 60 and 21 articles respectively. Sixteen countries made one contribution each. Seventeen articles have been contributed with multinational collaborations. The mean citation rate for the 100 top-cited articles was $529 \pm 62$. These 100 high-cited articles were published in 52 journals. The three top journals were New England Journal of Medicine 
with 15 articles, the Lancet with 12 articles, and JAMA - Journal of the American Medical Association with 9 articles. The main topics of the 100 high-cited articles were clinical characteristics, diagnosis, prognosis, and epidemiological aspects of Covid-19. Among the 100 top-cited articles, 13 and 87 articles pertained to the basic and clinical sciences respectively. Johnson, Sakya, Sakya, Onkendi and Hallan ${ }^{7}$ identified and examined 100 most-cited publications on Covid-19, using both Scopus and Web of Science database and using R-Studio and Bibliometrix for statistical analysis. The top 100 most-cited articles were published in 50 different journals from over 25 countries. They identified the most contributing countries, organizations, authors and the top 5 five most productive journals and the extent of international collaborations involved in such studies. This study will also provide an educational guide to facilitate effective evidence-based medical research and offer insight into the developments of Covid-19 research. ElHawary, Salimi, Diab and $\mathrm{Smith}^{8}$ summarized the characteristics of the top 50 high-cited Covid-19-related publications that emerged early during the pandemic, by making a systematic search of the Web of Science, Scopus, and Google Scholar. Data extracted included the type of study, journal, number of citations, number of authors, country of publication, and study content. As of May $29^{\text {th }}$, the top 50 cited articles were cited 63849 times during the last 4 months. On an average, 14 authors contributed to each publication. Over half of the identified articles were published in only 3 journals. Furthermore, $42 \%$ and $26 \%$ of the identified articles were retrospective case series and correspondence/viewpoints, respectively, while only 1 article was a randomized controlled trial. In terms of content, almost half $(48 \%)$ of the identified publications reported clinical/radiological findings while only 7 out of the 50 articles investigated potential treatments. Borku Uysal, Islamoglu, Koc. et al. ${ }^{9}$ bibliometrically analyzed the top 100 most-cited articles, based on their altmetric attention scores and dimension badge scores, using top 100 articles from 27387 articles from Web of Science and PubMed databases till August 31, 2020. They determined the number of citations of top 100 articles, their main topics, the universities that published them, the scientific journals they were published and their level of evidence, social media interests, and the number of citations-Altmetric score correlations.

So far no comprehensive bibliometric study is available on high-cited papers in Covid-19. Most studies cover data pertaining to a few months' period and are restricted to the analysis of top 50-200 high-cited papers. As a result, we decided to undertake the present study which covers all high-cited papers published during 2020-21.

\section{MATERIALS AND METHODS}

The publications data on HCPs for the study was sourced from Web of Science. The research papers on Covid-19 were searched using keywords such as Covid-19, novel ccoronavirus, coronavirus disease, severe acute respiratory syndrome coronavirus 2 , and SARS-CoV-2. The search was conducted on metadata fields including title, abstract, author keywords, keywords plus. In this process, a total of 127205 records were retrieved from the database covering the publication period 2019-21. The citations to these publications were counted since their publication till 2021.

Some of the studies have defined a high-cited paper (HCP) as one of such cited papers that belong to the top $1 \%$ category of total papers in a research field and published in a specified year. But in this study a highcited paper is defined as one that had accrued 100 or more citations since its publication in 2019. In all, there were 1625 such papers, out of a total of 127205 records retrieved on Covid-19 research. Each of 1625 papers received 100 or more citations since its publication. These 1625 papers account for a $1.27 \%$ share of the total output. The publication data pertaining to such 1625 records was downloaded to Microsoft Excel and subsequently statistically analysed. The data was also analysed using VOSviewer, a software tool for constructing and visualizing bibliometric networks. In WoS, papers are distributed into 22 research fields and an article can be assigned to only one field.

TS = ("Covid 19" or "2019 novel Coronavirus" or "Coronavirus 2019" or "coronavirus disease 2019" or "2019-novel CoV" OR "2019 ncov" or "covid 2019" or "covid19" or "corona virus 2019" or "ncov-2019" or "ncov2019" or "nCoV 2019" or "2019-ncov" or "covid-19" or "Severe acute respiratory syndrome coronavirus 2" or "SARS-CoV-2")

\section{RESULTS}

Of the 1625 HCPs that appeared during 2019-21, a 3.38\% share (55 papers) accrued 1000 - 9147 citations per paper, 7.75\% (126 papers) received 501-1000 citations per paper, and the remaining 89\% (1344 papers) received 100-500 citations per paper (Figure 1). A WoS screenshot of top 8 most HCPs shows that these papers were published in as late as March - July 2020 (Figure 1). A short list of most high-cited papers is given in Table 1.

\section{Subject-Wise Distribution}

The 1625 HCPs on Covid-19 are distributed over 22 WoS research fields. Medicine general accounts for the most HCPs, a share of $20.49 \%$, followed by infectious diseases (12.18\%), immunology (7.51\%), etc. (Table 2).

\section{Most Important Journals}

The 1625 HCPs on Covid-19 were published in 460 journals. The distribution of HCPS by reporting journals is widely scattered. For instance, as many as 400 journals published just 1-5 papers each, 41 published 6-9 papers each, 10 published 10-28 papers each, and barely 9 journals published 29 - 75 papers each. Table 3 shows top 15 productive journals along with HCPs each journal published and citations received. New England Journal of Medicine is the most productive journal, it published 75 HCPs. Lancet and JAMA rank second with 65 HCPs and $55 \mathrm{HCPs}$ respectively in the list of top 15 productive journals. New England Journal of Medicine accrued the most (43220) citations with an average of 576.27 citations per paper.

\section{Top 10 Countries}

The 1625 HCPs papers on Covid-19 are distributed across 91 countries. The distribution by country of publication is highly skewed. The top three countries the USA, China, the UK alone account for the most productivity with a combined $88 \%$ share of total HCPs. The. USA is the top most productive country with 595 HCPs (a $36.6 \%$ share of 1625 HCPS). China ranks second with $582 \mathrm{HCPs}$ (a $35.8 \%$ share). The top 10 productive countries are listed in Table 4 (Figure 2). In terms of citations accrued, it is the China that ranks top in the tally with most 212351 citations.

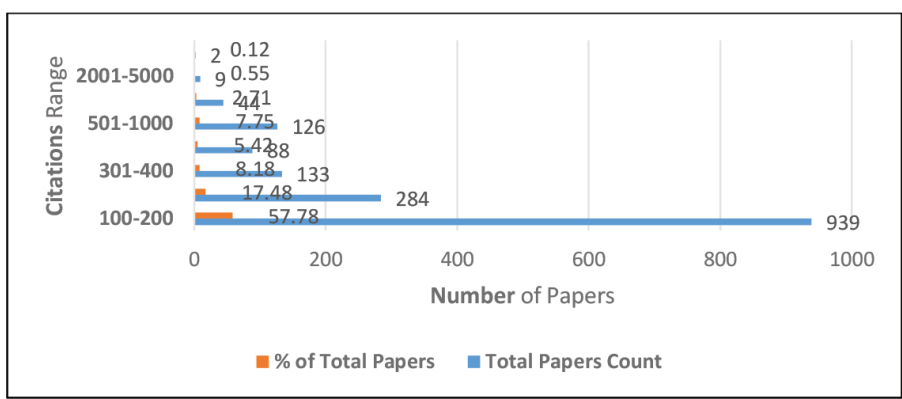

Figure 1 : Distribution of HCPs by Citation Range. 
Table 1: Top High-Cited Research Papers in Covid-19 2019-21.

\begin{tabular}{|c|c|c|}
\hline \# & Date / Author / Journal & GCS \\
\hline 1 & $\begin{array}{l}335 \text { Guan W, Ni Z, Hu Y, Liang W, Ou C, et al. Clinical Characteristics of Coronavirus Disease } 2019 \text { in China NEW ENGLAND JOURNAL OF } \\
\text { MEDICINE. } 2020 \text { APR 30; } 382 \text { (18): 1708-1720 }\end{array}$ & 9147 \\
\hline 3 & $\begin{array}{l}262 \mathrm{Wu} \text { ZY, McGoogan JM, Characteristics of and Important Lessons From the Coronavirus Disease } 2019 \text { (Covid-19) Outbreak in China } \\
\text { Summary of a Report of } 72314 \text { Cases From the Chinese Center for Disease Control and Prevention, JAMA-JOURNAL OF THE AMERICAN } \\
\text { MEDICAL ASSOCIATION. } 2020 \text { APR 7; } 323 \text { (13): 1239-1242 }\end{array}$ & 4767 \\
\hline 5 & $\begin{array}{l}232 \mathrm{Xu} \text { Z, Shi L, Wang YJ, Zhang JY, Huang L, et al. Pathological findings of Covid-19 associated with acute respiratory distress syndrome, } \\
\text { LANCET RESPIRATORY MEDICINE. } 2020\end{array}$ & 3002 \\
\hline 6 & $\begin{array}{l}604 \text { Richardson S, Hirsch JS, Narasimhan M, Crawford JM, McGinn T, et al. Presenting Characteristics, Comorbidities, and Outcomes Among } \\
5700 \text { Patients Hospitalized With Covid-19 in the New York City Area, JAMA-JOURNAL OF THE AMERICAN MEDICAL ASSOCIATION. } 2020 \\
\text { MAY 26; } 323 \text { (20): 2052-2059 }\end{array}$ & 2294 \\
\hline 8 & $\begin{array}{l}1037 \text { Wu CM, Chen XY, Cai YP, Xia JA, Zhou X, et al. Risk Factors Associated With Acute Respiratory Distress Syndrome and Death in Patients } \\
\text { With Coronavirus Disease } 2019 \text { Pneumonia in Wuhan, China JAMA INTERNAL MEDICINE. } 2020 \text { JUL; } 180 \text { (7): } 934-943\end{array}$ & 2289 \\
\hline 9 & $\begin{array}{l}812 \text { Long QX, Liu BZ, Deng HJ, Wu GC, Deng K, et al. Antibody responses to SARS-CoV-2 in patients with Covid-19, NATURE MEDICINE. } \\
2020 \text { JUN; } 26 \text { (6): 845-+ }\end{array}$ & 2257 \\
\hline 10 & $\begin{array}{l}1026 \text { Gautret P, Lagier JC, Parola P, Hoang V, Meddeb L, et al. Hydroxychloroquine and azithromycin as a treatment of Covid-19: results of an } \\
\text { open-label non-randomized clinical trial, INTERNATIONAL JOURNAL OF ANTIMICROBIAL AGENTS. } 2020 \text { JUL; }\end{array}$ & 2204 \\
\hline
\end{tabular}

Table 2: Covid-19 Research: Distribution of HCPS across WoS Subject areas.

\begin{tabular}{|c|c|c|c|}
\hline Subject Area & $\begin{array}{l}\text { Share of } \\
\text { HCPs \% }\end{array}$ & HCPs Count & $\begin{array}{c}\text { Citations } \\
\text { Count }\end{array}$ \\
\hline Medicine General Internal & 20.49 & 333 & 144092 \\
\hline Infectious Diseases & 12.18 & 198 & 54490 \\
\hline Multidisciplinary Sciences & 7.69 & 125 & 36676 \\
\hline Immunology & 7.51 & 122 & 38043 \\
\hline Microbiology & 6.71 & 109 & 28695 \\
\hline Biochemistry Molecular Biology & 5.48 & 89 & 24652 \\
\hline $\begin{array}{l}\text { Public Environmental } \\
\text { Occupational Health }\end{array}$ & 5.42 & 88 & 21185 \\
\hline Psychiatry & 4.92 & 80 & 20494 \\
\hline Virology & 4.31 & 70 & 16131 \\
\hline Cardiac Cardiovascular Systems & 4.25 & 69 & 19077 \\
\hline Medicine Research Experimental & 4.12 & 67 & 19360 \\
\hline Environmental Sciences & 3.57 & 58 & 12477 \\
\hline Pharmacology Pharmacy & 3.02 & 49 & 14667 \\
\hline Hematology & 2.89 & 47 & 13397 \\
\hline Respiratory System & 2.77 & 45 & 14075 \\
\hline Neurosciences & 2.09 & 34 & 8195 \\
\hline Clinical Neurology & 2.03 & 33 & 7285 \\
\hline Surgery & 1.85 & 30 & 7123 \\
\hline Pediatrics & 1.78 & 29 & 8011 \\
\hline Oncology & 1.42 & 23 & 4767 \\
\hline Health Care Sciences Services & 0.98 & 16 & 2622 \\
\hline
\end{tabular}

Table 3: Covid-19 Research - Top 15 Productive Journals Reporting HCPs.

\begin{tabular}{lccc}
\hline Journal & Records & Citations & $\begin{array}{c}\text { CPP by } \\
\text { JL }\end{array}$ \\
\hline New England Journal of Medicine & 75 & 43220 & 576.27 \\
Lancet & 65 & 32027 & 492.72 \\
JAMA-Journal of the American Medical & 55 & 31346 & 569.93 \\
Association & & & \\
Science & 43 & 12710 & 295.58 \\
Nature & 40 & 12039 & 300.98 \\
Journal of Medical Virology & 38 & 9183 & 241.66 \\
Clinical Infectious Diseases & 33 & 8096 & 245.33 \\
Science of the Total Environment & 31 & 5365 & 173.06 \\
Bmj-British Medical Journal & 29 & 8000 & 275.86 \\
Lancet Infectious Diseases & 26 & 11101 & 426.96 \\
Nature Medicine & 26 & 9284 & 357.08 \\
Journal of Infection & 23 & 5562 & 241.83 \\
Radiology & 23 & 8899 & 386.91 \\
Cell & 18 & 5740 & 318.89 \\
Lancet Respiratory Medicine & 18 & 7237 & 402.06 \\
\hline
\end{tabular}

The USA in the second position with 163422 citations. The collaboration between countries has been measured in terms of total collaborative link strength. It represents the number of connections between a given country and the countries it collaborated with. The total link strength of top 10 collaborating countries varied between 163 and 804 links. The USA had the most collaboration density with a total of 804 links, followed by the China (529) and U.K (598). The citation interactions between top 
10 countries are measured in terms of total citations links strength. For these top 10 countries, it varies between 1316 and 8498 citations links. Interestingly the top 10 most productive countries are also the top 9 most cited countries in the world (Table 4, Figure 2).

\section{Centres of Excellence}

At the institution level, the $1625 \mathrm{HCPs}$ were contributed by authors from 3479 organizations around the world. Top 20 most productive organizations in this list account for a $51 \%$ share of the total HCPs. Seven of these organizations were from China, five each from the USA and UK, and one each from Singapore, Hong Kong, and Italy.

These top 20 organizations were ranked on their productivity in HCPs and also on citations that these organizations received during the period.

Table 4: Covid-19 Science Research: A Profile of Top 10 Productive Countries 2019-21.

\begin{tabular}{|c|c|c|c|c|c|c|c|}
\hline$\sum_{\sim}^{0}$ & 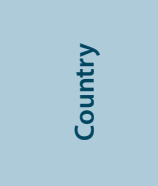 & $\begin{array}{l}\stackrel{n}{I} \\
\text { }\end{array}$ & 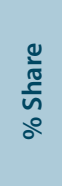 & 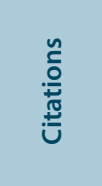 & ì & 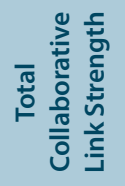 & 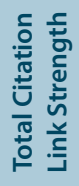 \\
\hline 1 & USA & 595 & 36.6 & 163422 & 274.66 & 804 & 8498 \\
\hline 2 & China & 582 & 35.8 & 212351 & 364.86 & 529 & 9278 \\
\hline 3 & UK & 253 & 15.6 & 78493 & 310.25 & 598 & 4243 \\
\hline 4 & Italy & 196 & 12.1 & 48462 & 247.26 & 420 & 2962 \\
\hline 5 & Germany & 118 & 7.3 & 37234 & 315.54 & 400 & 2258 \\
\hline 6 & France & 100 & 6.2 & 27330 & 273.3 & 320 & 1810 \\
\hline 7 & Canada & 83 & 5.1 & 22851 & 275.31 & 311 & 1561 \\
\hline 8 & Australia & 71 & 4.4 & 18980 & 267.32 & 290 & 1220 \\
\hline 9 & Netherlands & 70 & 4.3 & 23510 & 335.86 & 288 & 1644 \\
\hline 10 & Switzerland & 60 & 3.9 & 18736 & 312.27 & 163 & 1316 \\
\hline
\end{tabular}

Both the listings were compared for their productivity performance and citations performance. The study found that eleven out of the top 20 organizations from the high-productivity organizations list were also listed in the high-cited organizations list. This implies that eleven of these organizations are in common to both the listings; these must be recognized as the centres of excellence in COVID science research around the world. The names of these eleven organizations are; (1) Huazhong University of Science \& Technology, China (107 papers), (2) Wuhan University, China (76 papers), (3). Harvard Medical School, USA (59 papers), (4) University of Oxford, U.K. (46 papers), (5). Icahn School of Medicine at Mount Sinai, USA (41 papers), ( 6) Chinese Academy of Sciences (38 papers), (7) University College London (UCL), U.K. (34 papers), (8) Sun Yat- Sen University, China (33 papers), (9) Capital Med University, China (32 papers), (10) Shanghai Jiao Tong University, China (30 papers) and (11) University of Washington, USA (30 papers). These may be regarded as the centres of excellence in Covid-19 medical science research. (Table 5, Figure 3)

Figure 3 represents the relationship between organizations (nodes), a bidirectional intensity of asymmetric collaboration. The font size of the node is proportional to the volume of its publications and citations. The

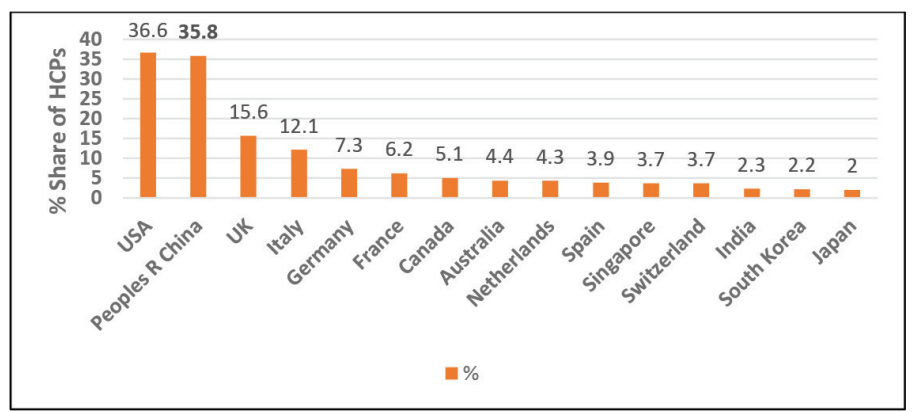

Figure 2: Covid-19 Research: Share of HCPS by Country of Publication.

Table 5: Covid-19 Research - Global List of Centres of Excellence.

\begin{tabular}{|c|c|c|c|c|c|c|c|}
\hline$\#$ & Institution & Country & Records & $\%$ Share & Citations & $\begin{array}{l}\text { Most Productivity } \\
\text { Rank }\end{array}$ & $\begin{array}{c}\text { Most Citations } \\
\text { Rank }\end{array}$ \\
\hline 1 & Huazhong Univ Sci \& Technol & China & 107 & 6.6 & 49284 & 1 & 1 \\
\hline 2 & Wuhan Univ & China & 76 & 4.7 & 23521 & 2 & 3 \\
\hline 3 & Harvard Med Sch & USA & 59 & 3.6 & 19230 & 3 & 6 \\
\hline 4 & Univ Hong Kong & K.Kong & 57 & 3.5 & 28728 & 4 & 2 \\
\hline 5 & Univ Oxford & U.K. & 46 & 2.8 & 19165 & 5 & 7 \\
\hline 6 & Icahn Sch Med Mt Sinai & USA & 41 & 2.5 & 12972 & 6 & 19 \\
\hline 7 & Chinese Acad Sci & China & 38 & 2.3 & 10964 & 7 & 11 \\
\hline 8 & Fudan Univ & China & 34 & 2.1 & 10972 & 8 & 0 \\
\hline 9 & UCL & UK & 34 & 2.1 & 14287 & 9 & 16 \\
\hline 10 & Columbia Univ & USA & 33 & 2 & 10808 & 10 & 0 \\
\hline 11 & Sun Yat Sen Univ & China & 33 & 2 & 18807 & 11 & 8 \\
\hline 12 & Capital Med Univ & China & 32 & 2 & 19622 & 12 & 5 \\
\hline 13 & Imperial Coll London & U.K. & 32 & 2 & 9362 & 13 & 0 \\
\hline 14 & Natl Univ Singapore & Singapore & 32 & 2 & 10325 & 14 & 0 \\
\hline 15 & Univ Milan & Italy & 31 & 1.9 & 9737 & 15 & 0 \\
\hline 16 & Shanghai Jiao Tong Univ & China & 30 & 1.8 & 12475 & 16 & 20 \\
\hline 17 & University Washington & USA & 30 & 1.8 & 13007 & 17 & 18 \\
\hline 18 & Univ Cambridge & U.K. & 29 & 1.8 & 11262 & 18 & \\
\hline 19 & Kings College London & U.K. & 29 & 1.8 & 9628 & 19 & 0 \\
\hline 20 & Stanford University & USA & 29 & 1.8 & 7554 & 20 & 0 \\
\hline
\end{tabular}

Note - Organizations in bold font are in common to both the listings, ranked on productivity of HCPs and ranked on most cited organizations. 
size of concentric circles reflects their collaboration rate. The node color means that it belongs to an aggregate cluster (institutional sector). Every node is placed in the space according to its dependence. The closeness or distance between the circles is related to the total number of links of

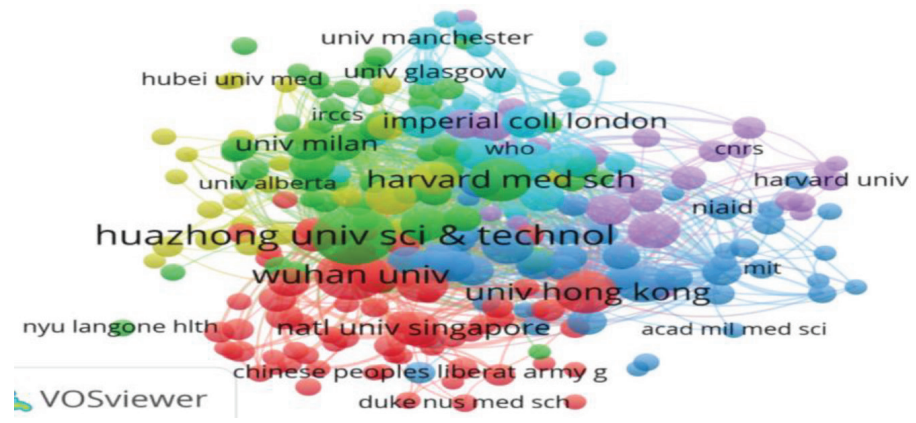

Figure 3: Network Analysis of Organizations in HCPs on Covid-19. an organization with the others. The lower left part of the representation shows the different levels of aggregation that the user can choose in order to develop analysis by sector.

\section{Keywords Analysis}

Table 6 shows keywords used in HCPs to characterize Covid-19 research along with the frequency of their occurrence, their per cent share in the overall HCPs output, and the citations the keyword received during the period. The most common keywords used are Covid, Patients, CoV, clinical and China. Keyword analysis is important because it opens up a secondary approach to understand and find evidence regarding research trends in the subject (Figure 4).

Co-occurrence of keywords is a concept which refers to the common presence, frequency of occurrence, and close proximity of similar keywords present across HCPs (Table 7). Biblioshiny software tool was used for co-occurrence analysis (Figure 5). The network co-occurrence link strength of keywords is very strong varying between 272 and 2600 links.

Table 6: Keywords used in HCPs to Characterize Covid-19 Science Research.

\begin{tabular}{|c|c|c|c|c|c|c|c|c|c|}
\hline$\#$ & Keyword & Records & $\%$ Share & Citations & $\#$ & Keyword & Records & $\%$ Share & Citations \\
\hline 1 & Covid & 1277 & 78.6 & 363391 & 31 & Pneumonia & 50 & 3.1 & 16328 \\
\hline 2 & Coronavirus & 343 & 21.1 & 116863 & 32 & Impact & 48 & 3 & 10674 \\
\hline 3 & Patients & 330 & 20.3 & 110880 & 33 & Cases & 46 & 2.8 & 19222 \\
\hline 4 & Sars & 302 & 18.6 & 89930 & 34 & Hospitalized & 44 & 2.7 & 20386 \\
\hline 5 & Cov & 287 & 17.7 & 84329 & 35 & Human & 44 & 2.7 & 12049 \\
\hline 6 & Disease & 258 & 15.9 & 92534 & 36 & New & 43 & 2.6 & 13798 \\
\hline 7 & Clinical & 149 & 9.2 & 64211 & 37 & Systematic & 43 & 2.6 & 12368 \\
\hline 8 & Pandemic & 135 & 8.3 & 29369 & 38 & Mortality & 40 & 2.5 & 21547 \\
\hline 9 & China & 128 & 7.9 & 67067 & 39 & Children & 39 & 2.4 & 10404 \\
\hline 10 & Severe & 118 & 7.3 & 36819 & 40 & Evidence & 39 & 2.4 & 8775 \\
\hline 11 & Infection & 111 & 6.8 & 29303 & 41 & Based & 38 & 2.3 & 12663 \\
\hline 12 & Health & 107 & 6.6 & 26513 & 42 & Epidemic & 38 & 2.3 & 13766 \\
\hline 13 & Review & 94 & 5.8 & 27764 & 43 & Factors & 38 & 2.3 & 22196 \\
\hline 14 & Outbreak & 90 & 5.5 & 27971 & 44 & Features & 37 & 2.3 & 12031 \\
\hline 15 & Acute & 75 & 4.6 & 23028 & 45 & Meta & 36 & 2.2 & 10038 \\
\hline 16 & Novel & 73 & 4.5 & 18577 & 46 & Immune & 35 & 2.2 & 9920 \\
\hline 17 & Analysis & 72 & 4.4 & 20629 & 47 & Italy & 34 & 2.1 & 11144 \\
\hline 18 & Characteristics & 69 & 4.2 & 40703 & 48 & Severity & 34 & 2.1 & 7938 \\
\hline 19 & Risk & 69 & 4.2 & 25473 & 49 & Management & 33 & 2 & 8381 \\
\hline 20 & Associated & 68 & 4.2 & 24755 & 50 & Cohort & 32 & 2 & 18079 \\
\hline 21 & Respiratory & 68 & 4.2 & 24602 & 51 & Diagnosis & 32 & 2 & 8144 \\
\hline 22 & Syndrome & 66 & 4.1 & 22649 & 52 & Effect & 32 & 2 & 7238 \\
\hline 23 & Treatment & 65 & 4 & 20600 & 53 & System & 32 & 2 & 8475 \\
\hline 24 & Care & 62 & 3.8 & 14850 & 54 & Vaccine & 31 & 1.9 & 7765 \\
\hline 25 & TransmissiON & 55 & 3.4 & 17042 & 55 & Viral & 31 & 1.9 & 10511 \\
\hline 26 & Wuhan & 55 & 3.4 & 30220 & 56 & Cell & 30 & 1.8 & 8216 \\
\hline 27 & Mental & 54 & 3.3 & 15371 & 57 & Global & 30 & 1.8 & 7678 \\
\hline 28 & Outcomes & 52 & 3.2 & 18796 & 58 & Early & 29 & 1.8 & 7041 \\
\hline 29 & Potential & 52 & 3.2 & 13630 & 59 & Hospital & 29 & 1.8 & 7976 \\
\hline 30 & Case & 50 & 3.1 & 11467 & 60 & Psychological & 29 & 1.8 & 8097 \\
\hline
\end{tabular}




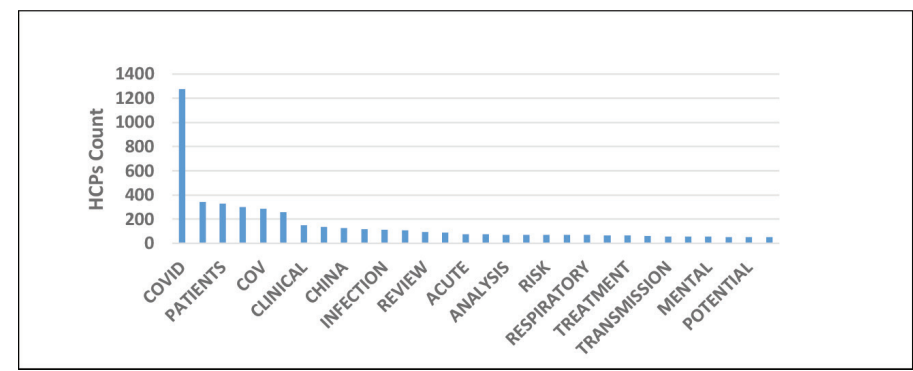

Figure 4: Distribution of HCPs by Keywords in COVID Reseach.

Table 7: Keyword Co-occurrence Analysis of HCPs in Covid-19 Science Research.

\begin{tabular}{lcc}
\hline Keyword & Occurrences & Total Link Strength \\
\hline Covid-19 & 555 & 2600 \\
Coronavirus & 371 & 1786 \\
SARS-CoV-2 & 283 & 1535 \\
Pneumonia & 213 & 1246 \\
SARS & 177 & 1000 \\
Acute Respiratory Syndrome & 116 & 621 \\
Infection & 112 & 601 \\
Outbreak & 93 & 578 \\
Respiratory Syndrome & 64 & 452 \\
Coronavirus & & \\
China & 86 & 451 \\
\hline
\end{tabular}

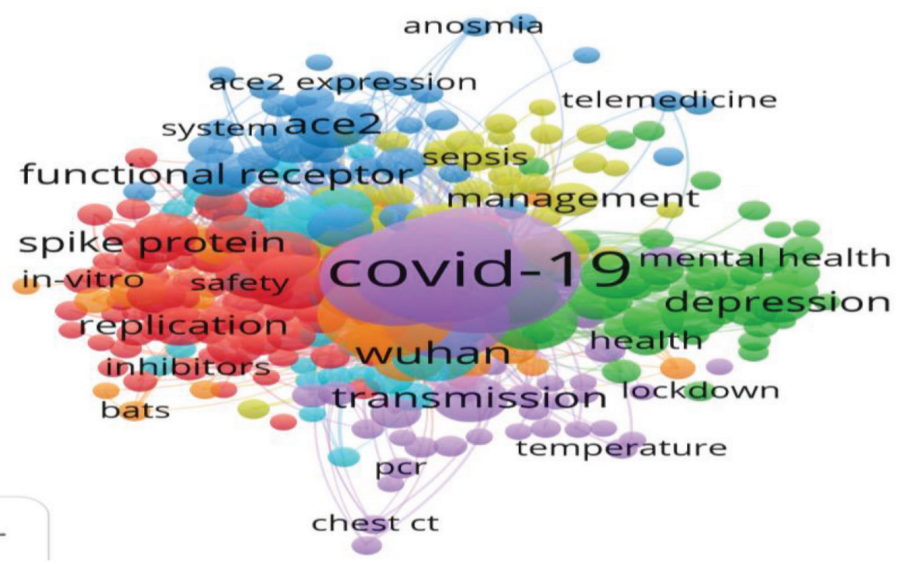

Figure 5: Network Analysis of Keyword Occurrences in HCPs on Covid-19.

\section{SUMMARY}

This study has analysed HCPs in Covid-19 research using bibliometric indicators with the aim to identify key countries and organizations in
Covid-19 research. The analysis is based on research publications data published during 2019-21. The research data was sourced from Web of Science. Only such cited papers were covered in this study which accrued 100 or more citations per paper. The Covid-19 research by subject covered in HCPs is focused on top select areas involving medicine-general internal, infectious diseases, immunology and microbiology. The USA, China, and the UK dominate global Covid-19 research in terms of productivity of HCPs. But evaluating their performance in terms of citations received, China leads the tally with the USA at the second position. The USA, China, and the U.K. together account for an $88 \%$ world share of HCPs in the subject. The study identified top 11 centers of excellence based on the criterion of most productivity of HCPs by an organization coupled with the criterion of most citations that an organization received for HCPs it published. Four of eleven organizations each are located in USA and China, and one each in the UK, Italy and Hong Kong. The eleven organizations are Huazhong University of Science and Technology, Wuhan University, Harvard Medical School, University of Oxford, Icahn School of Medicine, Mt Sinai, Chinese Acadaemy of Sciences, University College London, Sun Yat- Sen University, Capital Medical University, Shanghai Jiao Tong University and University of Washington. These organizations may be regarded as the centres of excellence in Covid-19 medical science research. The most favored research journals for publication of HCPs are New England Journal of Medicine, Lancet, JAMA-Journal of The American Medical Association, Science and Nature. The relationship networks of most productive organizations and keywords based on VOSviewer software are also given.

\section{REFERENCES}

1. Else H. Nature. How a torrent of COVID science changed research publishing in seven charts. 2020;588(7839):553. doi: 10.1038/d41586-020-03564-y, PMID 33328621.

2. Wohlin C. An analysis of the most cited articles in software engineering journals-1999. Inf Softw Technol. 2005;47(15):957-64. doi: 10.1016/j. infsof.2005.09.002.

3. Farooq KR, Ashiq M, Siddique N, Rehman, Shafiq Ur A, Hafiz M, Ajmal Khan M. A bibliometric review of high-cited and hot papers on coronavirus and Covid-19. Library Philosophy and Practice (e-journal). Available from: https:// digitalcommons.unl.edu/libphilprac/5238. Vol. 5238; 2021.

4. Ram S, Nisha F. High-Cited Articles in Coronavirus Research. DESIDOC JI Lib Info Technol. 2020;40(4):218-29. doi: 10.14429/djlit.40.04.15671.

5. Kambhampati SBS, Vasudeva N, Vaishya R, Patralekh MK. Top 50 cited articles on Covid-19 after the first year of the pandemic: A bibliometric analysis. Diabetes Metab Syndr. 2021;15(4):102140. doi: 10.1016/j.dsx.2021.05.013.

6. Afshar A, Tabrizi A. Bibliometric analysis of the 100 high-cited articles about Covid-19. Arch Bone Jt Surg. 2020;8(6):748-56. doi: 10.22038/abjs.2020.51846.2556, PMID 33313359.

7. Johnson T, Sakya S, Sakya J, Onkendi E, Hallan D. The top 100 most cited articles on Covid-19. The Chronicles. 2020;8(35):42-50. doi: 10.12746/swrccc. v8i35.739.

8. ElHawary H, Salimi A, Diab N, Smith L. Bibliometric Analysis of Early COVID-19 Research: The Top 50 Cited Papers. Infect Dis (Auckl). October 2020;13:1178633720962935. doi: 10.1177/1178633720962935, PMID 33110348.

9. Uysal BB, Islamoglu MS, Koc S, Karadag M, Dokur M. Most notable 100 articles of Covid-19: an altmetric study based on bibliometric analysis. Ir J Med Sci. 2021. doi: 10.1007/s11845-020-02460-8, PMID 33459942. 